Saudi Journal of Nursing and Health Care

Abbreviated Key Title: Saudi J Nurs Health Care

ISSN 2616-7921 (Print) |ISSN 2616-6186 (Online)

Scholars Middle East Publishers, Dubai, United Arab Emirates

Journal homepage: https://scholarsmepub.com/sjnhc/

Original Research Article

\title{
Effect of Educational Protocol to Improve Mothers' Knowledge, Practice and Attitude about Child Abuse
}

Reda El-Said El-badawy Ezzat

Lecturer of Community Health Nursing, Faculty of Nursing, Zagazig University, Egypt

\begin{tabular}{ll}
\hline DOI: $10.36348 /$ sjnhc.2019.v02i11.007 & | Received: 21.11.2019| Accepted: 28.11.2019| Published: 30.11 .2019 \\
*Corresponding author: Reda El-Said El-badawy Ezzat &
\end{tabular}

Abstract

Background: Child abuse is a serious problem causing physical, social and psychosocial harm to the children. Aim: To evaluate the effect of educational protocol in improving mothers' knowledge, practice and attitude about child abuse. Design: A quasi-experimental research design [pretest -posttest] was used. Setting: At the out patient's clinics at Zagazig University Hospitals. Sample: A purposive sample consisted of 100 mothers participated in this study and they were chosen according to inclusion criteria. Tools: Four tools were used; Interview questionnaire sheet, Mother's knowledge about child abuse, Child Abuse Prevention Attitude Scale, Check List for Expressed Practices on Child Abuse. Results: Revealed that most of the mothers were secondary education, house wives and from rural areas, there were statistical significant differences between prelposttests regarding knowledge, practice, attitudes for the mothers regarding child abuse and there was negative association among the incidence of child abuse and the level of knowledge, practice, and attitude of their mothers. Conclusion: The applying of educational protocol for mothers was effective in enhancing their knowledge, practice, and attitudes regarding child abuse. Recommendation: Educational pamphlets about child abuse and its prevention strategies should be given to mothers in different settings such as, clinics, worksites and health care centers, and also establishing child abuse prevention programs at schools could be helpful.

Keywords: Attitude, Child abuse, Educational protocol, Knowledge and Practice.

Copyright @ 2019: This is an open-access article distributed under the terms of the Creative Commons Attribution license which permits unrestricted use, distribution, and reproduction in any medium for non-commercial use (NonCommercial, or CC-BY-NC) provided the original author and source are credited.

\section{INTRODUCTION}

Childhood is a critical phase of human life, during which personality features are developed, therefore, a silent and safe transition requires the support of family and community [1]. Child abuse or child maltreatment is physical, sexual, or psychological maltreatment or neglect of a child or children, especially by a parent or other caregiver. Child abuse may include any act or failure to act by a parent or other caregiver that results in actual or potential harm to a child, and can occur in a child's home or in the organizations, schools, or communities the child interacts with (World Health Organization) [2]. The World Health Organization (WHO) defines child abuse and child maltreatment as "all forms of physical and/or emotional ill-treatment, sexual abuse, neglect or negligent treatment or commercial or other exploitation, resulting in actual or potential harm to the child's health, survival, development or dignity in the context of a relationship of responsibility, trust or power [1]. Child abuse may cause stress, leading to changes in the nervous, cardiovascular, and immune systems, and metabolism, and would form inappropriate personality features and increase risk behaviors among children [3].

Children most prone to abuse are children from poor families, working children, children without Families, children of alcoholic parents, children in broken families, abandoned children, delinquent and street children. They can be exploited, sexually abuse, engaged in beggary, emotionally abused or put into child marriage, also they can be abused by antisocial elements by forcing them into drug trafficking, begging, hawali and vending [4].

Mothers can play an important role in child abuse prevention through monitoring, reduction of risk factors, guidance, and education about prevention strategies [5].

Many studies indicate that mothers could provide their children with warnings, teaching about dangerous situations, and how to handle the incidents of abuse [6]. It is well documented that mothers who have enough knowledge about child abuse, effectively 
discuss safety measures with their children and therefore improve the children's self- protection skills [7], contrary to the mothers who don't have this knowledge. In some Arab countries, there is lack of information about the knowledge of Arabian mothers about prevention practices and education related to child abuse, also it is unknown if mothers actually educate their children sufficiently about abuse or if they consider it a taboo [5].

Mothers' practice and attitude of child abuse influence their understandings of this problem and their actions to protect their children [8]. As the family structure is Egypt ranges from nuclear to extended family structure, it is difficult to anticipate the sources and risks of exposure to child abuse [5].

Parental attitudes are also important factors in the prediction of parental child abuse. As a general rule, more favorable attitudes and subjective norms, and greater perceived behavioral control, strengthen the individual's intentions to perform a behavior. According to the theory of planned behavior, attitude is one of the main causes of a behavior [9].

Mothers should always take care of their children and notice their behavior and make them aware of indicators of abuse to be able to avoid abusive instances. Indicators of abuse could be any unusual scar mark or hurt on child's body, irritated behavior and weird behavior to detect early abuse and prevent it as soon as possible. Hence mothers' knowledge, practice and attitude are very important to know indicators of child abuse, signs and symptoms in children suffering from abuse, furthermore, in protecting their children from any type of abuse [10].

Educational protocols for parents whose objective is to inform the parents about child abuse; provides parents and children with the education and support necessary for healthy family functioning. Based on what is known or believed to enhance an individual's ability to function within the family unit, several program areas contributing to the strategy can be identified. Beginning with the prenatal period, these programs offer a continuum of educational, supportive and therapeutic services for parents and children enduring throughout the school years [11].

Nurses have moral and legal responsibilities to educate the mothers about this topic and also to report these cases to relevant governmental authorities or social welfare organizations to provide early interventions for victims and perpetrators and prevent further abuse [1].

\section{Significance of the Study}

Child abuse is a serious problem causing physical, social and psychosocial harm to the children and also to their families. The incidence of child abuse is increasing, reported, about $4-16 \%$ of children are physically abused and one in ten are neglected or psychologically abused [10], therefore, the aim of the study was to evaluate the effect of educational protocol in improving mothers' knowledge, practice and attitude about early detection of child abuse

\section{Hypothesis}

- Educational protocol for mothers improves their knowledge, attitude, and practice about child abuse.

\section{AIM OF THE STUDY}

The study was conducted to evaluate the effect of educational protocol in improving mothers' knowledge, practice and attitude about child abuse.

\section{The aim of this study was full filled through the following objectives}

- Assessed knowledge, attitude, and practice of mothers about child abuse.

- Designed an educational protocol for mothers to enhance their knowledge, attitude, and practice.

- Evaluated the effect of the sessions for the mothers.

\section{SUBJECTS AND METHOD Design} conduct this study.

Quasi experimental design was used to Setting

The outpatienst clinics at Zagazig University Hospitals, at Zagazig city.

\section{Sample}

A total sample of 100 mothers was recruited to participate in this study. The sample size was determined according to the following equation:

$\mathbf{N}=(\mathbf{Z} \alpha)^{2} \times \mathbf{p} \mathbf{q} / \mathbf{d}^{2}$, (Sahai and Khurshid, 1996) [12].

The estimated sample sizes will be:

$\mathrm{n}=$ sample size.

$\mathrm{Z} \alpha=$ the value of standard normal distribution for

type I error probability for the sided test and equals 1.96 .

$\mathrm{p}=26 \%$.

$\mathrm{q}=1-\mathrm{p}$

$\mathrm{d}^{2}=$ the accuracy of estimate $=(0.05)^{2}$

This subject was chosen according to the following criteria:

\section{Inclusion Criteria}

- Providing care to the child \& Living with the child in the same dwelling.

- Having at least a child in school age (4-12 
years old).

- Aged between 20 and 40 years old.

- Regular attendance to the clinic.

- Verbal accepting taking part in the protocol.

- Not sharing in other similar protocols.

\section{Exclusion criteria}

- Mothers with handicapped children

\section{Tools for Data Collection}

Interview Questionnaire sheet: It was developed by the investigator, it was consisted of two parts:-

First part: This part was about demographic characteristics of mothers; included questions such as education's level, residence, age, employment status, and marital status.

Second part: The characteristics of the studied child; that consist of some questions like: sex, and age.

\section{Tool (II): Mother's knowledge about child abuse}

This tool was developed by Abdullah et al., [10]; consists of 15 Arabic questions. It included questions such as: definition of child abuse, difference between child abuse and discipline, sources of mothers' knowledge, what are the forms of child abuse, what are the physical, emotional, neglect, sexual indicators, what are the family, \& environmental factors of child abuse.

\section{Scoring System}

Knowledge questionnaire sheet was consisted of 15 questions. The scores of the items was summed up and the total was divided by the number of items giving a means of score for the part. Theses scores were converted into percent score, means and standard deviations was computed

Total scores were accounted according to the following:

- Good is $>75 \%$ of total knowledge score.

- Fair is from 60-75\% of total knowledge score.

- Poor $<60 \%$ of total score.

\section{Tool (III): Child Abuse Prevention Attitude Scale}

This tool was originally developed by Kaleeswari [13]; consisted of 10 items; included items such as Child abuse need not to be given importance, Child abuse will obstruct the development of the child Abused, child may become an mentally depressed, Improve family income through child labor, Child abuse is more only in low income groups, Punishment is only way for mistake, Early life of child abuse will result in scar in future, Parents have the rights to beating the child, Abused child may become an anti-social adult and Parents will taught about the sexual abuse to their children. The scale was translated into Arabic by the researcher.

\section{Scoring system:}

Responses were measured in all questions on five points Likert scale; Strongly Disagree, Agree scored, Strongly Agree, Slightly Agree, and Slightly Disagree. The correct answer of each question carries' five' marks and the wrong answer is marked' one'. The maximum score is 50 .

Total score was accounted according to the following:

- $\quad$ Positive attitude is $\geq 60 \%$ of total score.

- Negative attitude is $<60 \%$ of total attitude score.

\section{Tool (IV): Check List for Expressed Practices on Child Abuse}

This tool was originally developed by Kaleeswari [13]; consists of 10 items; included items such as I avoid sending a child along with the strangers, I have taught my child good touch and bad touch, I avoid beating the child, I discriminate male and female child, and I attend to the teacher and discuss about my child school behaviors. The scale was translated into Arabic by the researcher.

\section{Scoring System}

Scoring: The answers with either "Yes" or "No"; The correct answer of each question carries' one' mark and the wrong answer is marked' zero'. The maximum score 10. Total scores were accounted according to the following:

- Unsatisfactory is $<60 \%$ of total practice score.

- Satisfactory is from $60-75 \%$ of total practice score.

- Highly satisfactory is $>75 \%$ of total practice score.

\section{Content validity}

The validity of tools had done through five expertise professors of Community Health Nursing Specialties, and Psychiatric Mental Health Nursing Specialties, from different Faculties of Nursing. The tools were modified based on their guidance and views.

\section{Reliability}

All tools for data collection were tested for its reliability using test retest reliability and all tools were proved to be strongly reliable. This was done using the assessment of their internal consistency. The reliability proved to be high based on the values of (Cronbach alpha coefficients $=0.871$ ).

\section{Field work}

1. The researcher conducted an intensive review of the past and current related literature covering various aspects of the "child abuse" and associated parental knowledge, attitude and practice. This was done using available textbooks and articles in scientific periodicals and journals. Based on this review, the tools were prepared in their preliminary forms, and 
reviewed by a panel of nursing and medical specialists for face and content validation. The review also helped in developing a basic framework of the educational protocol.

2. Informed oral consent was obtained from the participants.

3. The investigator met with the subjects, introduced herself and explained the purpose of the study to obtain their consent to participate in the study and gain their cooperation and confidence.

4. The participants were interviewed individually before applying the planned sessions to collect the baseline data using all study tools.

5. The researcher started to fill-out the questionnaire from sample. The researcher read and explained each item to the mothers and recorded their responses to each item. This interview took about 25 to 30 minutes.

6. The execution of the study was through four phases, namely assessment, planning, implementation, and evaluation. This lasted for 6 months and half from the first of March 2019 to the end of August 2019.

7. The objective of the protocol was to improve knowledge, practice, and attitude of the mothers.

8. The protocol was implemented in the form of 13 sessions. The duration of each session ranged between thirty minutes and forty-five minutes. The protocol was implemented in small homogeneous groups in the outpatient clinic; each group consisted of 5-10 mothers according to their attendance. The sessions were administered twice per week for each study group. They were held on Saturdays, and Wednesdays.

9. The protocol was implemented through various teaching methods as short lectures, group discussions, brain storming, demonstration redemonstration, and role-play. The teaching media included power-point presentations and a handbook.

10. Each session was started by a summary about what was given through the previous session and the objectives of the new one to make sure that mothers recognize the content, taking into consideration the use of simple language to suit the educational level of mothers. Motivation and reinforcement techniques as praise and recognition were used during the session to enhance participation and learning.

11. The researcher designed an illustrative booklet in simple Arabic language to be distributed to caregivers.

\section{Description of the protocol}

\section{General Objective of the Program}

To improve knowledge, practice, attitude of the mothers about Child Abuse.

\section{Specific Objectives}

By the end of this program:

- The mothers will be able to discuss simple information about child abuse.

- The mothers will be able to summarize the main problems with their children regarding to the focused problem.

- The mothers will be able to deal correctly with their children behavioral.

- The mothers will be have positive attitude regarding child abuse.

\section{The Protocol Sessions Consisted of Two Main Components}

- The first component was for giving a theoretical background of child abuse such as definition, patterns, effects and types, complications; (this included 5 sessions)

- The second main component was for giving practical sessions about parental attitudes, and practices of mothers regarding child abuse (this included 6 sessions).

- $\quad$ There were 2 sessions for starting and ending the protocol sessions.

\section{Evaluation phase}

- Immediately after the end of the sessions. Evaluation was done to assess the impact of the protocol.

\section{Ethical Considerations}

- Anonymity, confidentiality and privacy of the mothers were assured.

- Voluntary participation and right to refuse to participate in the study was emphasized to the subjects.

- Verbal consent was taken at the beginning of the study from mothers.

\section{STATISTICAL ANALYSIS}

Data entry and statistical analysis were done using SPSS 20.0 statistical software package.

\section{RESULTS}

Table-1 showed the distribution of demographic characteristics of mothers' children in the study sample. The table showed that the mean age of the children was $8.4158 \pm 2.38267$, and about $73.00 \%$ of them were males. 
Table-1: Distribution of socio-demographic characteristics of mothers' children in the study sample $(n=100)$

\begin{tabular}{|l|l|l|}
\hline Demographic characteristics & Frequency & \% \\
\hline Age (in years) & 9 & 9.00 \\
\hline $4-<6$ & 60 & 60.00 \\
\hline $6-<10$ & 31 & 31.00 \\
\hline $10-12$ & $8.4158 \pm 2.38267$ \\
\hline Mean \pm SD & \multicolumn{2}{|l|}{} \\
\hline Gender & 27 & 27.00 \\
\hline Female & 73 & 73.00 \\
\hline Male
\end{tabular}

Table-2 showed the demographic characteristics of studied mothers; the table showed that $72.00 \%$ of the mothers were aged between 35 to 40 years old. Also, about $61.00 \%$ of them were from rural areas, and about $71.00 \%$ of them were housewives.

\section{Table-2: Demographic characteristics of studied} mothers $(\mathbf{n}=\mathbf{1 0 0})$

\begin{tabular}{|l|l|l|}
\hline Items & No & $\%$ \\
\hline Age of mothers (in years) & & \\
\hline $20:<25$ & 13 & 13.00 \\
\hline $25:<30$ & 0 & 0.00 \\
\hline $30:<35$ & 15 & 15.00 \\
\hline $35: 40$ & 72 & 72.0 \\
\hline Marital status & & \\
\hline Married & 51 & 51.00 \\
\hline Divorce & 32 & 32.00 \\
\hline Widow & 17 & 17.00 \\
\hline Occupation & & \\
\hline Working & 29 & 29.00 \\
\hline House wife & 71 & 71.00 \\
\hline Residence & 61 & 61.00 \\
\hline Rural & 39 & 39.00 \\
\hline Urban
\end{tabular}

Figure-1 illustrated that, $62.3 \%$ of the studied mothers had secondary level of education, while $6.5 \%$ of them were illiterates.

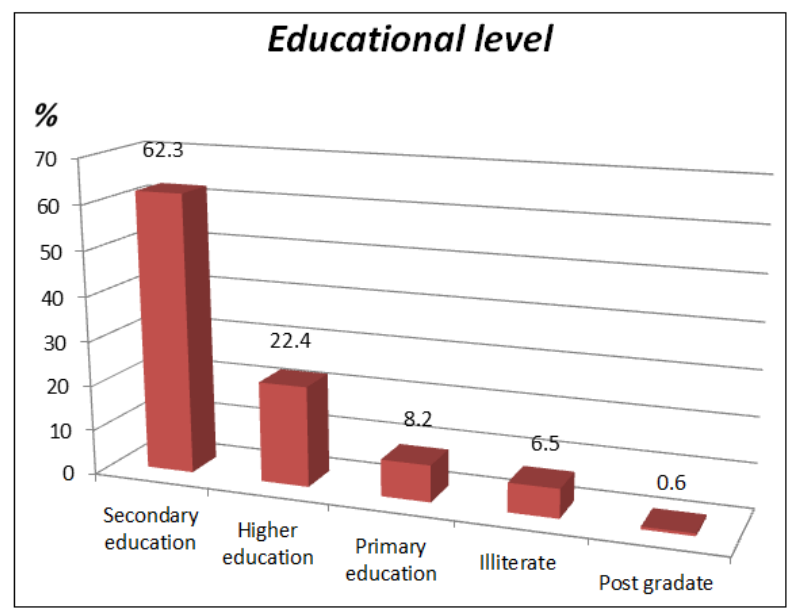

Fig-1: Distribution of studied mothers according to their educational level $(n=100)$
Figure-2 showed that less than half of studied mothers $(43.9 \%)$ received their knowledge from friends, while, the minority $(3.9 \%)$ of them received knowledge from the internet.

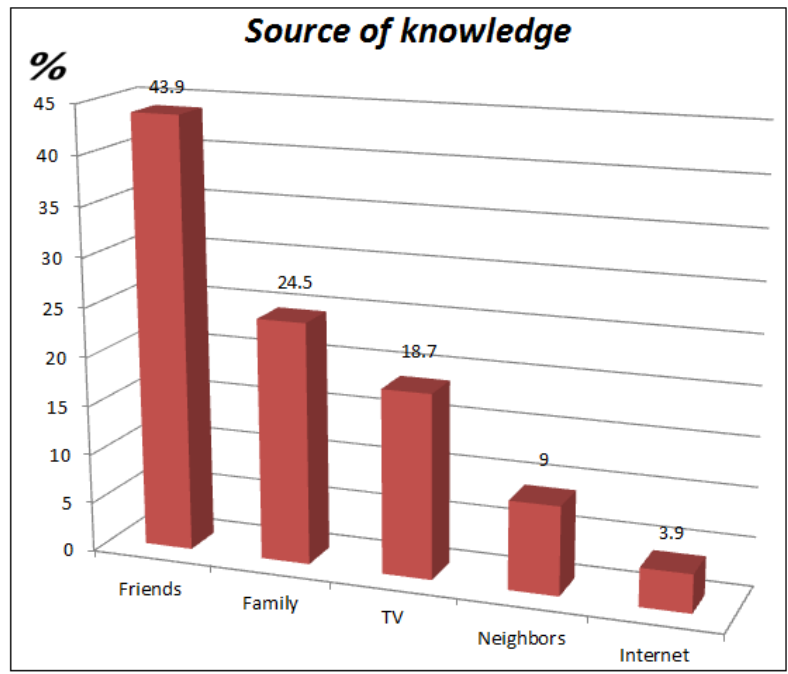

Fig-2: Distribution of the studied mothers according to their source of knowledge regarding child abuse $(n=100)$

Figure-3 showed knowledge score of the study subjects. The figure revealed statistically significant totally improvements in the mothers' knowledge regarding child abuse at $(\mathrm{p}<0.001)$ in the postintervention phase. Overall, none of parents $(0.00 \%)$ had good knowledge before the intervention and this increased to $64.6 \%$ after the intervention. Also, the fair knowledge degree increased from $14.6 \%$ to $35.4 \%$.

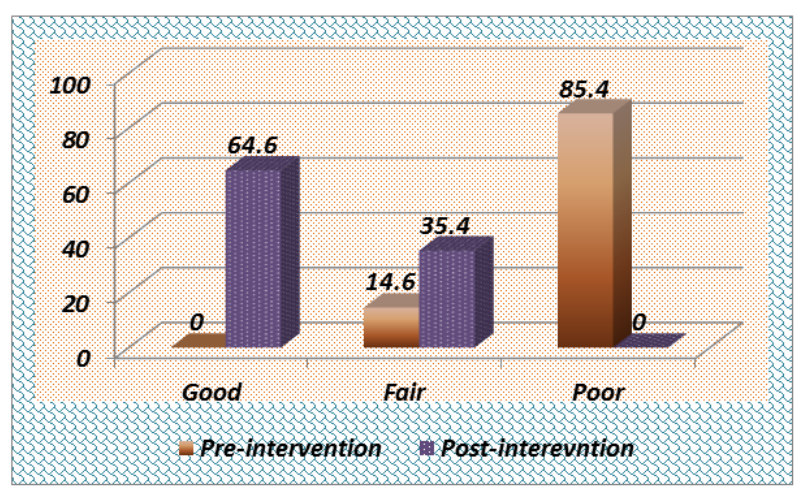

Fig-3: Total knowledge score of the study sample $(n=100)$

Figure-4 showed the total negative and positive attitude of the mothers of study subjects. The figure revealed statistically significant totally improvements in the mothers' attitudes regarding child abuse at $(\mathrm{p}<0.001)$ in the post-intervention phase. Overall, the total positive attitudes of the mothers increased from $35.4 \%$ at the pre phase to $89.6 \%$ after the intervention. 


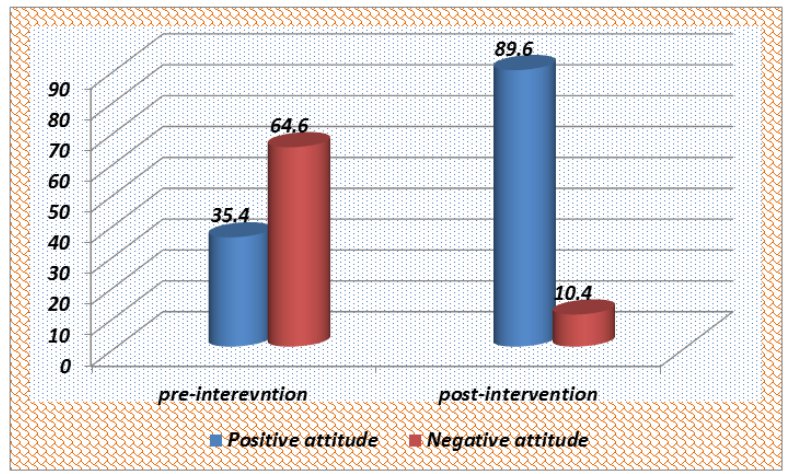

Fig-4: Total negative and positive attitude of the mothers of the study sample $(n=48)$

Figure-5 showed the score of mothers' practices toward child abuse in the study subjects. The figure revealed statistically significant totally improvements in the mothers' practices regarding child abuse at $(p<0.001)$ in the post-intervention phase. Overall, the percent of parents that feel highly satisfactory about their practice regarding child abuse increased from $6.3 \%$ at the pre phase to $83.3 \%$ after the intervention.

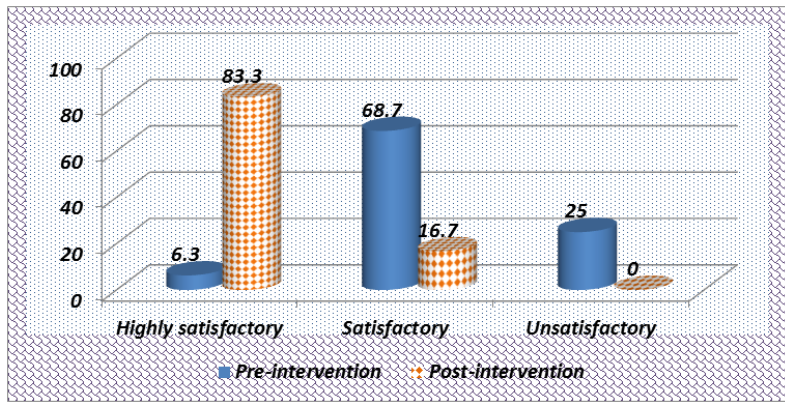

Fig-5: Total score of mothers' practices in the study sample, $(\mathbf{n}=\mathbf{1 0 0})$

Table-3 displayed the correlation among the incidence of child abuse and practice, knowledge, attitude of the mothers in the study subjects. It demonstrated that there was negative association among the incidence of child abuse and the level of knowledge, practice, and attitude of their mothers. This means when the knowledge, practice, attitude of the mothers increased, the incidence of child abuse will be decreased .

Table-3: Correlation among Child abuse and practice, knowledge, attitude of the mothers in the study sample $(\mathbf{n}=\mathbf{1 0 0})$

\begin{tabular}{|l|l|l|l|l|l|l|l|l|}
\hline \multirow{2}{*}{ Variable } & \multicolumn{2}{l|}{ Child abuse } & \multicolumn{2}{l|}{ Practice } & \multicolumn{2}{l|}{ Knowledge } & \multicolumn{2}{l|}{ Attitude } \\
\cline { 2 - 9 } & $\mathbf{r}$ & P value & R & P value & R & P value & R & P value \\
\hline Child abuse & 1 & & $-.793^{* *}$ & .000 & $-.795^{* *}$ & .000 & $-.875^{* *}$ & .000 \\
\hline Practice & $-.793^{* *}$ & .000 & 1 & & $.840^{* *}$ & .000 & $.882^{* *}$ & .000 \\
\hline knowledge & $-.795^{* *}$ & .000 & $.840^{* *}$ & .000 & 1 & & $.851^{* *}$ & .000 \\
\hline Attitude & $-.875^{* *}$ & .000 & $.882^{* *}$ & .000 & $.851^{* *}$ & .000 & 1 & \\
\hline
\end{tabular}

\section{DISCUSSION}

Childhood is a golden and enjoyable period of life. Protection of a child during this period is the responsibility of the parents especially their mothers who care for the child. Beside the parents, teachers and physicians play a very important role. Child abuse and child neglect have negative psychological effect on children [1].

Regarding to the demographic characteristics of the studied subjects, the present study showed that the mean age of the children of studied mothers was $8.4158 \pm 2.38267$, and more than half of them were males.These findings agreed with Abdullah et al., [10], in their Egyptian study at Suez Canal University; who revealed that the mean age of the children of the mothers was $7.3958 \pm 2.48176$ and more than half of them were males. On other hand, Khosravan et al., [14], disagreed with these finding as they found in their study that about two thirds of their mothers' children were females.

Also, the present study showed that most of $(72.9 \%)$ of the mothers in the sample was aged between 35 to 40 years old.
This finding disagreed with Kaleeswari [13]; in their study in selected village at Sivakasi. They reported that about less than half of their sample was aged between 26 to 30 years old. Furthermore, Jacob and Kumar [15], revealed that about (42\%) of the mothers were in the age group of 20-25 years, in their study to assess the knowledge regarding child abuse among mother's in selected residential areas of Delhi.

Regarding to educational level of the studied mothers, the present study illustrated that more than half of them had secondary level of education.

This finding was disagreed with Das [16], who revealed in his descriptive study that more than half of them had primary level of education, and only third of his sample had secondary level of education.

Regarding the residence of the studied subjects, the recent results showed that nearly two thirds of the mothers $(58.3 \%)$ were from rural areas.

This finding might be attributed to the setting of data collection in Zagazig University Hospitals at ElSharkia governorate which characterized by its agricultural nature and most of its cities are rural areas. 
The finding was in the same line with Mohan et al., [17], in their study about knowledge, attitude and practices on prevention of child sexual abuse among mothers in a teritiary setting, as they mentioned that their participants were from rural areas.

Additionally, the recent study illustrated that about more than half of the subjects were housewives.

This finding disagreed with Das [16], who found in his study at a selected rural community, in West Bengal, that, the majority of his studied subjects were workers. Also, Alzoubia et al., [5] reported that only about third of their Jordan study's mothers were unemployed.

The present study also revealed that less than half of studied mothers $(43.9 \%)$ received their knowledge from friends, while, the minority $(3.9 \%)$ of them received knowledge from the internet.

This is might be due to the natural of the studied characteristics of mothers in our study; as more than half of them had secondary level of education and were housewives; so they might not having the chance for other sources and the most available one is friends.

This finding was congruent with Das [16]; who reported in his study for assessment of knowledge regarding child abuse and its prevention among mothers of selected rural community, West Bengal, that, the minority $(3.0 \%)$ of the studied subjects received their knowledge about child abuse from the internet.

The home is supposed to provide support and safety for children but can also be the place where children suffer abuse and other adverse treatment by their parents [18]. An encouraging environment offered by a good mother child relationship is essential for the mental health of a developing individual. At the same time, the importance of the family for proper growth and development of a child cannot be undetermined [4].

Regarding mother's knowledge about child abuse before the educational protocol, the finding of the current study revealed that the majority of the study subjects had poor knowledge, and only about $14.6 \%$ of them had fair level of knowledge.

This poor level of knowledge could be explained by the mothers' low educational level in the current study (secondary level of education) as mentioned before. This exp; anation is supported by the National Academy of Sciences [19]; that reviewed mothers' educational level is important contributing factor towards child abuse and neglect. Additionally, they suggested that children belonging to low parents' educational status were more abused as compared to the children from high parents' educational level. Furthermore, the high rate of false beliefs that are spread around the child abuse, likewise the misinterpretation and misconceptions of its types, could also explained that poor results in mother's knowledge; as many mothers believed that neglect or psychological insult doesn't considered abuse. As well as, this result could explained related to insufficient mother's awareness regarding stages of growth and development of the child and also because of the Egyptian culture that considered some types of abuse especially sexual abuse as a stigma and shame to the victim and his all family.

Similarly to these present findings, Abdullah et al., [10], in their Egyptian study at Suez Canal University; reported that the majority $(84.8 \%)$ of mothers had totally unsatisfactory knowledge about child abuse. Also, Guo et al., [20] revealed in their study in China that the parents lacked knowledge about child sexual abuse prevention. Additionally, Devi and Yadav [4], found in their study to assess the knowledge of parents regarding child abuse; that only $8 \%$ of the studied parents had good knowledge.

On other hand, the recent results disagreed with Das [16], who mentioned in his results that most of the mothers in his study had average knowledge about child abuse and its prevention. Moreover, Alzoubia et al., [5] revealed in their Jordan study about sexual abuse that the majority of mothers were knowledgeable about children sexual abuse and its prevention practices. Also, Gurung and Bahattarai [21], conducted a descriptive cross sectional study on assessment of knowledge of child abuse among parents of children under 5 years of age residing in Kalanki area, Kathmandu, and found in their results that more than half of their participants had good knowledge about child abuse.

Fortunately, these poor results of mothers' knowledge regarding child abuse were improved after the implementation of the educational sessions; as two thirds of the participants became having good level in their knowledge score, the other third became fair and no one had poor knowledge. These good amendments in the level of the participant's knowledge could elucidate the favorable impact of the educational sessions and how the subjects were interested and cooperative within the intervention.

In the same line with the results of the present study after the protocol Mlekwa et al., [22], revealed in their study in Tanzania about Knowledge, attitudes and practices of parents on child sexual abuse and its prevention, that the majority $(95.6 \%)$ of respondents had high knowledge regarding prevention of child sexual abuse.

On other hand, Kaushik, and Daniel [23], disagreed with our results as they mentioned in their study about Knowledge and Attitude of Mothers regarding Prevention of Child Sexual Abuse, that, the 
analysis revealed $90 \%$ of subjects had inadequate knowledge regarding child sexual abuse.

Parents' attitudes will affect the way in which they behave towards their children, and their negative behavior may result in negative outcomes for them [24].

Regarding mothers practices, the present study declared that most of the participant's mothers had satisfactory feel regarding the topic before the implementation of the protocol and after it, the majority of the subjects felt highly satisfactory about their practice regarding their children.

In disagreement with this finding Okiche et al., [25] mentioned in their study in Nigeria about Child sexual abuse: knowledge, perception and preventive practice of caregivers of children seen in a tertiary hospital in southeast Nigeria, that the practice of about, $26.6 \%$ of mothers was moderately adequate practice regarding prevention of child sexual abuse, and only $11.8 \%$ of the caregivers had CSA preventive and sex talks with their children regularly. Also, Mlekwa et al., [22], reported in their study that only about a quarter $(27.3 \%)$ of respondents had good practices on protection and prevention of child sexual abuse

Regarding the attitude of the parents of the study sample; the results of the current study revealed that more than two thirds of the parents had negative attitudes, before the implementation of the sessions.

This could be due to their lack of knowledge about the problem as mentioned before in the recent results.

In disagreement with these results, Kaushik and Daniel [23], reported in their study that $90 \%$ of their subjects had positive attitude regarding prevention of child sexual abuse. Additionally, Mlekwa et al., [22], revealed in their study in Tanzania that the majority $(98.7 \%)$ of the respondents had positive attitudes on preventing child sexual abuse.

Fortunately, the sessions of the educational protocol of the study positively changed the mothers' attitudes; as the majority of the study sample changed to have positive attitudes after the protocol. This could profess the success of these sessions and declare the positive effect of the protocol on the participants. Also, this positive change reflexes the formidable role of education in improving the attitudes toward the problem of child abuse.

This finding in the same line with Khosravan et al., [14], who found in their study that after the intervention, the overall score of parenting attitudes was found to be significantly increased $(\mathrm{P}<0.001)$, and the prevalence of most abusive behaviors towards children was significantly reduced $(\mathrm{P}<0.05)$ in the intervention group compared to the control group.

This finding disagreed with the results mentioned by Jabraeili et al., [9], as they showed that mothers' attitudes toward child abuse were negative; in other words, the mothers disagreed with physical or emotional child abuse and neglect.

Cultural differences and common beliefs about parenting styles could be responsible for the difference in results regarding the knowledge, practices and attitudes of mothers regarding the problem of child abuse. In some countries, violence and stressful form of punishment, is common. Such explanation for the cultural differences could be supported by the view of Hyland et al., [26] in which they believed that parental attitudes and knowledge have important role in parental behavior and parenting styles.

Regarding the correlation among child abuse and practice, knowledge, attitude of the mothers in the current study sample; it was demonstrated that there was negative association among the child abuse and the level of knowledge, practice, and attitude of their mothers. This means when the knowledge, practice, attitude of the mothers increased, the incidence of child abuse will be decreased. This negative correlation could easily reflex the importance of such educational sessions among mothers having children, and how these protocols positively affected the problem positively with the children and their families and control it.

In the same line with this finding, Khosravan et al., [14] and Cheraghi et al., [27], reported in their studies which focusing on parents' attitudes, knowledge, and practices regarding child abuse, that it was anticipated that changing attitudinal behavior, practices and knowledge, would lead to positive parental behavior and reduce the child abuse.

\section{CONCLUSION}

The study findings led to the conclusion that the mothers had poor knowledge, negative attitudes and unsatisfactory practices with child abuse before the protocol. Fortunately, the implementation of educational protocol was effective and enhanced their practice, knowledge, and attitudes. Moreover, the improvement in mothers' knowledge, practice, attitudes, was the predictor of the decreased of the the child abuse.

\section{RECOMMENDATION}

Based on the study findings, the following recommendations can be deduced:

- More similar studies and researches should be done in other settings to improve the knowledge, practice, and attitude of mothers regarding child abuse. 
- Educational pamphlets about child abuse and its prevention strategies should be given to mothers in different settings such as, clinics, worksites and health care centers.

- Establishing child abuse prevention programs at schools could be helpful.

\section{ACKNOWLEDGEMENTS}

We would like to thank all the mothers who participated in the study and staff of the out patients clinics at Zagazig University Hospitals for their help and cooperation during the study period.

\section{REFERENCES}

1. Alsaleem, S. A., Alsaleem, M. A., Asiri, A. M., Alkhidhran, S. S., Alqahtani, W. S., Alzahrani, M. S., ... \& Alsamghan, A. S. (2019). Knowledge and attitude regarding child abuse among primary health care physician in Abha, Saudi Arabia, 2018. Journal of family medicine and primary care, 8(2), 706-710.

2. World Health Organization (WHO). (2019). Violence and Injury Prevention. Child maltreatment (child abuse). Online Site. Retrieved from:https://www.who.int/violence_injury_prevent ion/violence/child/en/. Accessed on: 13\5\2019.

3. Ghezelseflo, M., \& Rostami, M. (2015). Relationship of child abuse with personality features and high risk behaviors in adolescents. Journal of Kermanshah University of Medical Sciences ( $J$ Kermanshah Univ Med Sci), 19(2), 93-101.

4. Devi, A., \& Yadav, R. (2016). Knowledge Regarding Child Abuse among Parents. International Journal of Advances in Nursing Management. 4(3):654-663.

5. Alzoubia, F., Alia, R., Flahb, I., \& Alnatour, A. (2018). Mothers' knowledge \& perception about child sexual abuse in Jordan. Journal of Child Abuse \& Neglect. 75(1):149-158.

6. Walsh, K., \& Brandon, L. (2012). Their children's first educators: Parents' views about child sexual abuse prevention education. Journal of Child \& Family Studies. 21(5):734-746.

7. Zhang, W., Chen, J., Feng, Y., Li, J., Zhao, X., \& Luo, X. (2013). Young children's knowledge and skills related to sexual abuse prevention: a pilot study in Beijing, China. Journal of Child Abuse Neglect. 37(9):623-630.

8. Ige, O. K., \& Fawole, O. I. (2011). Preventing child sexual abuse: parents' perceptions and practices in urban Nigeria. Journal of Child Sexual Abuse. 20(6): 695-707.

9. Jabraeili, M., Asadollahi, M., Jafarabadi, M., \& Hallaj, M. (2015). Attitude toward Child Abuse among Mothers Referring Health Centers of Tabriz. Journal of Caring Sciences. 4(1):75-82.

10. Abdullah, M., Abou-Abdou, S., \& Kafl, R. (2019). Assessment of Mothers' Knowledge about Early
Detection of Child Abuse. Unpublished thesisof Master degree in Psychiatric Nursing. Faculty of Nursing, Suez Canal University, 4-30.

11. Prevent Child Abuse America. (2019). Prevention Programs: An Approach to Prevent Child Abuse. Online Article. Retrieved from: https://preventchildabuse.org/resource/anapproach-to-prevent-child-abuse/. Accessed on: $1 \backslash 9 \backslash 2019$.

12. Sahai, H., \& Khurshid, A. (1996). Formulae and tables for the determination of sample sizes and power in clinical trials for testing differences in proportions for the two-sample design: a review. Statistics in medicine, 15(1), 1-21.

13. Kaleeswari, S. (2016). The level of knowledge, attitude and expressed practice regarding prevention of child abuse among mothers having school age children in selected village at Sivakasi. A masters thesis, Thanthai Roever College of Nursing, Perambalur. Retrieved from: http://repository-tnmgrmu.ac.in/3150/. Accessed on: $19 \backslash 5 \backslash 2019$.

14. Khosravan, S., Sajjadi, M., Moshari, J., \& Sofla, F. (2018). The Effect of Education on the Attitude and Child Abuse Behaviors of Mothers with 3-6 Year Old Children: A Randomized Controlled Trial Study. International Journal Community Based Nursing Midwifery, 6(3):227-238.

15. Jacob, J., \& Kumar, K. (2018). A study to assess the knowledge regarding child abuse among mother's in selected residential areas of Delhi-Ncr. Journal of Nursing and Health Science, 7(6):2931.

16. Das, D. (2017). Assessment of Knowledge Regarding Child Abuse and its Prevention among Mothers of Selected Rural Community, West Bengal. International Journal of Science and Research, 7(4):76-98.

17. Mohan, S., Kochuthresiamma, T., \& Joice, S. (2017): Knowledge, Attitude and Practices on Prevention of Child Sexual Abuse among Mothers in a Teritiary Setting. International Journal of Science and Research, 78(96):382-400.

18. Annerbäck, E. (2011). Child Physical Abuse, Characteristics, Prevalence, Health and Risktaking. Department of Clinical and Experimental Medicine Child and Adolescent Psychiatry, Linköping University, Sweden. Online published thesis, 23-80.

19. National Academy of Sciences. (2014). New Directions in Child Abuse and Neglect Research. Online Site. Retrieved from: https://www.ncbi.nlm.nih.gov/books/NBK195987/ . Accessed on: 10\7\2019.

20. Guo, S., Chen, J., Yu, B., Jiang, Y., Song, Y., \& Jin, Y. (2019). Knowledge, Attitude and Practice of Child Sexual Abuse Prevention among Parents of Children with Hearing Loss: A Pilot Study in Beijing and Hebei Province, China. Journal of child sexual abuse, 28(7), 781-798. 
21. Gurung, L. B., \& Bahattarai, S. (2015). Knowledge of child abuse among parents of Under 5 Years Children in Kathmandu, Nepal. Journal of Manmohan Memorial Institute of Health Sciences, 1(4), 9-13.

22. Mlekwa, F., Nyamhanga, T., Chalya, P., \& Urassa, D. (2016). Knowledge, attitudes and practices of parents on child sexual abuse and its prevention in Shinyanga district, Tanzania. Tanzania Journal of Health Research, 28(4):1-9

23. Kaushik, A., \& Daniel, S. (2017). Knowledge and Attitude of Mothers regarding Prevention of Child Sexual Abuse. International Journal of Nursing \& Midwifery Research, 4(4):1-20.

24. El Moneam, N. S. A., El-Fattah, S. R. A., ElBoraie, O. A., \& El-Etreby, R. R. Evaluation of Psycho-Educational Intervention for Children
Having Attention Deficit Hyperactivity Disorder and Their Parents, 80-88.

25. Okiche, C., Nwobashi, L., \& Ogugua, C. (2019). Child sexual abuse: knowledge, perception and preventive practice of caregivers of children seen in a tertiary hospital in southeast Nigeria. Journal of BMJ, 104(2): 3-24.

26. Hyland, M. E., Alkhalaf, A. M., \& Whalley, B. (2013). Beating and insulting children as a risk for adult cancer, cardiac disease and asthma. Journal of behavioral medicine, 36(6), 632-640.

27. Cheraghi, F., Rostaie, Z., Asgari, M., Shamsaei, F., \& Tapak, L. (2017). The Effect of Training of Parental Role on Mothers' Attitude with Children Aged 1-5 Years with Respect to Children'Abuse. Iranian Journal of Health Education and Health Promotion, 5(3), 182-190. 